\title{
Vascular Endothelial Growth Factor and Diabetic Nephropathy
}

\author{
Ioannis Griveas* \\ Consultant Nephrologist, Medical Director of Nephrology Department in 417 Army Share Fund Hospital, Athens, Greece
}

*Corresponding author: Ioannis Griveas, Consultant Nephrologist, Medical Director of Nephrology Department in 417 Army Share

Fund Hospital, Athens, Greece

\begin{tabular}{|c|c|}
\hline ARTICLE INFO & ABSTRACT \\
\hline Received: 㓞 February 03, 2020 & \\
\hline Published: 慧 February 07, 2020 & $\begin{array}{l}\text { Abbreviation: VEGF: Vascular Endothelial Growth Factor, PDGF: Platelet-Derived } \\
\text { Growth Factor, PLGF: Placental Growth Factor, GENC: Glomerular Endothelial Cell, PDR: } \\
\text { Proliferative DR }\end{array}$ \\
\hline
\end{tabular}

Citation: Ioannis Griveas. Vascular Endothelial Growth Factor and Diabetic Nephropathy. Biomed J Sci \& Tech Res 25(3)-2020. BJSTR. MS.ID.004200.

\section{Short Communication}

According to the edition of International Diabetes Federation Atlas in 2009, the estimated diabetes prevalence for 2010 had risen to 285 million, representing $6.6 \%$ of the world's adult population, with a prediction that by 2030 the number of people with diabetes in the world will have risen to 438 million1, with the majority of the new diabetic population coming from Asia. Diabetes-induced vascular dysfunction and pathologies are the major causes of morbidity and mortality in diabetic patients. Diabetic complications are a result of interactions among systemic metabolic changes, such as hyperglycemia, differential local tissue responses to toxic metabolites of glucose metabolism, and genetic and epigenetic modulators. Factors such as Vascular Endothelial Growth Factor (VEGF) seem to get involved in the above process.

\section{What is Vascular Endothelial Growth Factor (VEGF) system?}

Originally described as endothelial cell specific mitogen. VEGF belongs to the VEGF/Platelet-Derived Growth Factor (PDGF) supergene family, whose gene products are homodimers that share eight conserved cysteine residues. Actually, is a sub-family of growth factors, to be specific PDGF family of cystine-knot growth factors.

In humans, there are five secreted glycoproteins that make up the VEGF family member: VEGF-A, VEGF-B, VEGF-C, VEGF-D and Placental Growth Factor (PIGF). VEGF-E is encoded by certain viruses and its gene is not contained within the human genome. Native VEGF is a basic, heparin-binding homodimeric glycoprotein of $45 \mathrm{kDa}$. The most extensively studied of these family members is VEGF-A and if a person is referring generally to "VEGF" they are typically referring to VEGF-A. It is an important signaling protein mainly involved in angiogenesis. It also plays an important role in bone formation, wound healing, hematopoiesis and development. VEGF acts in a different way depending on the target. For example, it is produced by carcinoma cells, acts through paracrine signaling on endothelial cells and through autocrine signaling on carcinoma cells. Evidence shows that autocrine VEGF is involved in two major aspects of invasive carcinoma: survival and migration.

Moreover, it was shown that tumor progression selects for cells that are VEGF-dependent, challenging the belief that VEGF's role in cancer is limited to angiogenesis [1,2]. At the turn of this millennium, the role of Vascular Endothelial Growth Factor (VEGF) in the diabetic kidney seemed like it was going to be straightforward. VEGF was "up" in diabetic rats and blockade of its actions attenuated albuminuria: VEGF was "bad" in diabetic nephropathy. Since that time, our understanding of the complex paracrine signaling cascades that are mediated by the VEGF family has expanded. It has become apparent that it is not simply the amount of "VEGF" 
that is important, but also the type of VEGF, the sites of VEGF action and the context inwhich VEGF-mediated signaling occurs. These advances have provided a gold-standard framework against which our knowledge of the actions of other regulators of cellular function in the diabetic kidney can be compared.

\section{Glomerular Endothelial Cell Fenestrations}

FENESTRATIONS ARE THE DEFINING characteristic of the Glomerular Endothelial Cell (GEnC) both morphologically and functionally. Endothelial fenestrations can be grouped into three types according to type of endothelium and presence or absence of diaphragms (Table 1). It has been observed that high levels of VEGF expression are found in epithelial cells closely associated with fenestrated endothelia. The above notice led to the hypothesis that
VEGF induces endothelial fenestrations. The proposed pathway is shown in (Figure 1). It seems that there is a primary role for VEGF in maintenance of fenestrations as well as in their biogenesis. However, the question of whether GEnC fenestrations are dynamic structures is at present totally unexplored. The reduction in GFR associated with loss of fenestral area predicted by biophysical models does indeed occur in preeclampsia where there is good evidence that this is the mechanism of acute renal failure [3]. In this condition, increased circulating levels of soluble VEGFR1 bind to podocyte-produced VEGF and reduce availability for endothelial signaling [4]. This results in endothelial thickening and a reduction inboth size and density of fenestrations, "endotheliosis." GFR recovers as the condition resolves and fenestrations reappear.

Table 1: Comparison of the three types of endothelial cell fenestrations.

\begin{tabular}{|c|c|c|c|}
\hline \multicolumn{2}{|c|}{ Endothelium in Which Fenestrations are Expressed } \\
\hline & $\begin{array}{c}\text { Systemic Capillaries e.g. Gastrointestinal } \\
\text { and Renal peritubular }\end{array}$ & $\begin{array}{c}\text { Discontinuous Endothelium e.g. hepatic } \\
\text { sinusoidal }\end{array}$ & Discontinuous \\
\hline Endothelial type & Fenestrated & No & Fenestrated \\
\hline Diaphragm & Yes & No & 100-175 \\
\hline Diameter nm & $60-70$ & No (only in development) \\
\hline PV-1 expression & Yes & Yes \\
\hline Cytoskeletal ring & $?$ & Yes \\
\hline Cholesterol ring & $?$ & No (only in development) \\
\hline Basel lamina & Yes & No \\
\hline Glycocalyx & Yes & Yes \\
\hline
\end{tabular}

Note: V-1. plasmalernmal vesicle-associated protein-1: 7. unknown.

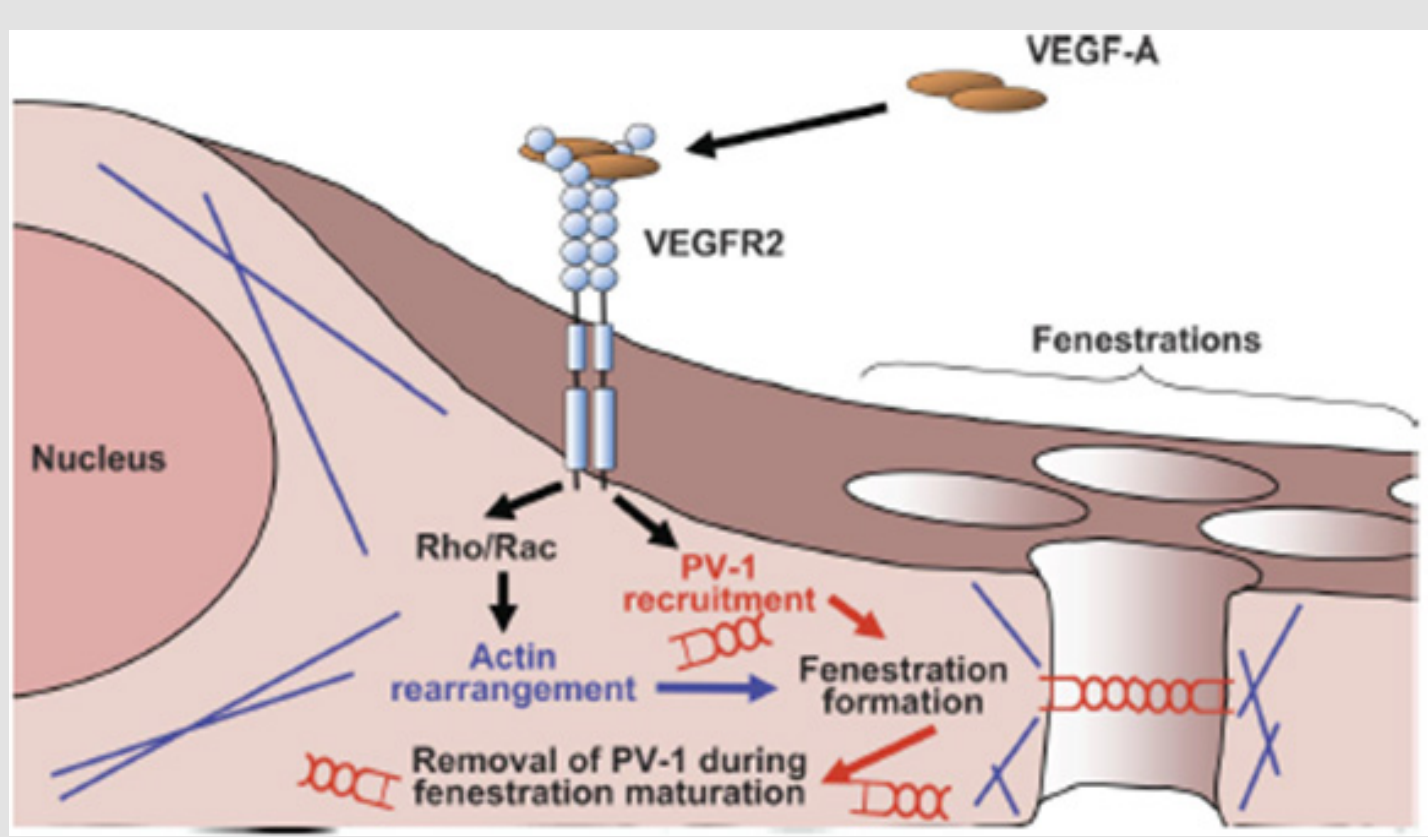

Figure 1: (GEnC). VEGF-A Binds and Activates VEGF receptor (VEGFR) 2. which leads. Via small protein CIPases. to actin MU-rangetnent required for formation of 2 fenestral cytoskeletal ring_ VEGFR2 activation also leads to recruiunent of plasmalemmal vesicle-associated protein-I PV-I) and PV-I multimer assembly in the forming fenestration_Fenestral diaphragms and PV-1 disappear as the fenestration matures. 


\section{The "Eye" Example}

Increased concentration of VEGF-A has been reported in the ocular fluids [4] and retinal tissues [5-8] of diabetic patients and is associated with the severity of Proliferative Dr (PDR). AntiVEGF treatment, including intravitreal injection, can inhibit the progression of PDR8. However, it is likely that retinal VEGF levels are initially elevated as a result of a reaction against retinal hypoxia or ischemia in diabetes to maintain endothelial function and circulation, as a result of pericytes loss and acellular capillaries. This increase in VEGF is probably a tissue response to increase survival. Thus, the use of chronic anti-VEGF therapies might have beneficial effects on the vasculature in the short-term. Clinically, the loss of VEGF without good glycemic control or a decrease of metabolic demands, as by photocoagulation, might cause complications in the neural retina (Figure 2).
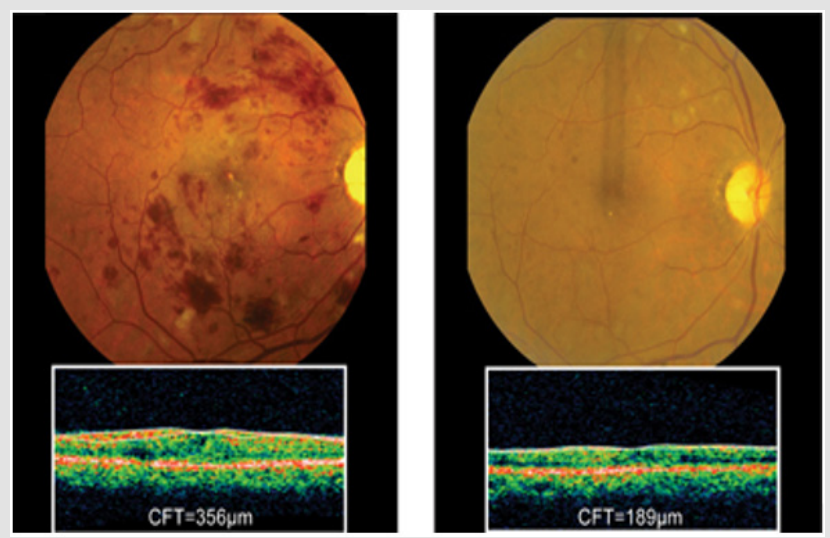

Figure 2.

\section{Bottom Line}

VEGF includes a family of growth factors that act on endothelial cells regulated by hypoxia and promote angiogenesis, increase permeability in vasculature, and is also known as a major regulator of endothelial proliferation, migration, and survival [9]. What is the physiological role of VEGF-A in the kidney, especially glomeruli? It is reported that treatment with anti-VEGF antibodies to patients with cancers [10] or within patients with preeclampasia [11] causes proteinuria and endothelial damage, suggesting that VEGF-A plays an important role in maintaining endothelial cell function and the glomerular filtration barrier. Supporting this, detailed reports by Quaggin et al. clearly show that VEGF-A is necessary for forming and maintaining the glomerular filtration barrier $[12,13]$.

\section{Is VEGF-A a bad or Good Player for The Progression of Diabetic Nephropathy?}

Although VEGF expression of glomeruli is upregulated during all stages (mild, moderate and severe) of nephropathy, VEGF bioactivity in endothelial cells is only increased in mildly injured glomeruli and decreased in moderate or severe lesions. Glomerular capillary rarefaction is linked to the degree of glomerulosclerosis and endothelial cell proliferation, showing capillary repair is markedly increased only in mildly/moderately injured glomeruli, even if apoptosis is detected in all stages. Diabetic nephropathy is associated with glomerular capillary rarefaction by an imbalance of endothelial cell proliferation, repair and apoptosis, and injury; and reduced VEGF activity might be an indicator of an insufficient capillary repair reaction [14]. Therefore, if increased VEGF expression occurs as a reaction of compensation for the damage of glomerular endothelial cells, inhibition of VEGF should not be given as a treatment for diabetic nephropathy. However, further studies are needed to conclude whether VEGF-A is or is not an endogenous protective factor for diabetic nephropathy.

\section{References}

1. (2009) International Diabetes Foundation.

2. Majumder S, Advani A (2017) VEGF and the diabetic kidney: More than too much of a good thing. Journal of Diabetes and Its Complications 31(1): 273-279.

3. Lafayette RA, Druzin M, Sibley R, Derby G, Malik T, et al. (1998) Nature of glomerular dysfunction in pre-eclampsia. Kidney Int 54(2): 1240-1249.

4. Stillman IE, Karumanchi SA (2007) The glomerular injury of preeclampsia. J Am Soc Nephrol 18: 2281-2284.

5. Aiello LP, Avery RL, Arrigg PG, Iwamoto MA, Park JE, et al. (1994) Vascular endothelial growth factor in ocular fluid of patients with diabetic retinopathy and other retinal disorders. N Engl J Med 331(22): 1480-1487.

6. Hammes HP, Lin J, Bretzel RG, Brownlee M, Breier G (1998) Upregulation of the vascular endothelial growth factor/vascular endothelial growth factor receptor system in experimental background diabetic retinopathy of the rat. Diabetes 47(3): 401-406.

7. Boulton M, Foreman D, Williams G, Mc Leod D (1998) VEGF localization in diabetic retinopathy. Br J Ophthalmol 82(5): 561-568.

8. Simo R, Hernandez C (2008) Intravitreous anti-VEGF for diabetic retinopathy: hopes and fears for a new therapeutic strategy. Diabetologia 51(9): 1574-1580.

9. Ferrara N (2004) Vascular endothelial growth factor: basic science and clinical progress. Endocr Rev 25(4): 581-611.

10. Zhu X, Wu S, Dahut WL, Parikh CR (2007) Risks of proteinuria and hypertension with bevacizumab, an antibody against vascular endothelial growth factor: Systematic review and metaanalysis. Am J Kidney Dis 49(2): 186-193.

11. Maynard SE, Min JY, Merchan J (2003) Excess placental soluble fms-like tyrosine kinase 1 (sFlt1) may contribute to endothelial dysfunction, hypertension, and proteinuria in preeclampsia. J Clin Invest 111(5): 649-658.

12. Eremina V, Sood M, Haigh J, Miner JH, Quaggin SE, et al. (2003) Glomerular-specific alterations of VEGF-A expression lead to distinct congenital and acquired renal diseases. J Clin Invest 111(5): 707-716.

13. Eremina V, Baelde HJ, Quaggin SE (2007) Role of the VEGF - a signaling pathway in the glomerulus: evidence for crosstalk between components of the glomerular filtration barrier. Nephron Physiol 106(2): 32-37.

14. Hohenstein B, Hausknecht B, Boehmer K, Riess R, Brekken RA, et al. (2006) Local VEGF activity but not VEGF expression is tightly regulated during diabetic nephropathy in man. Kidney Int 69: 1654-1661. 


\section{ISSN: 2574-1241}

DOI: 10.26717/BJSTR.2020.25.004200

Ioannis Griveas. Biomed J Sci \& Tech Res

(c) (P) This work is licensed under Creative

Submission Link: https://biomedres.us/submit-manuscript.php

$\begin{array}{ll}\text { BIOMEDICAL } & \text { Assets of Publishing with us } \\ \text { RESEARCHES } & \text { Global archiving of articles } \\ \text { - Immediate, unrestricted online access }\end{array}$

